\title{
Water Intake, Dietary Fibre, Defecatory Habits and its Association with Chronic Functional Constipation
}

\author{
VARSHA JANGID ${ }^{1}$, MEENA GODHIA ${ }^{1 *}$, \\ NEHA SANWALKA ${ }^{2}$ and AKASH SHUKLA ${ }^{3}$
}

\author{
${ }^{1}$ Department of Food, Nutrition and Dietetics, Sir Vithaldas Thackersey College of \\ Home Science, SNDT Women's University, Juhu Tara Road, \\ Santacruz (W), Mumbai, India. \\ ${ }^{2}$ Department of Nutrition and Biostatistics, NutriCanvas, Mumbai, India. \\ ${ }^{3}$ Department of Gastroenterology, Seth GS Medical College and KEM Hospital \\ Acharya Donde Marg, Parel, Mumbai 400012, India.
}

http://dx.doi.org/10.12944/CRNFSJ.4.2.02

(Received: May 14, 2016; Accepted: June 07, 2016)

\begin{abstract}
To study the association of water and fibre intake with defecatory habits of patients suffering from chronic functional constipation. A cross sectional study was conducted in 100 (51 females) adults suffering from chronic functional constipation. Using the questionnaire, information regarding defecatory habits of patients were collected. The Bristol stool scale was used to identify the type of stools the patient was passing. Dietary fibre intake was assessed by $24-\mathrm{h}$ recall on three random days. Dietary fibre intake (insoluble, soluble and total) was calculated. Total fluid intake throughout the day was also assessed. The mean age of the patients was $43.9 \pm 14.1$ years. Of the 100 patients, $80 \%$ of the patients suffered blockage while passing stools, $90 \%$ stressed to pass stools. $25 \%$ complained of blood in stools and $30 \%$ had satisfactory evacuation. Insoluble fibre intake was $28.2 \pm 11.7 \mathrm{~g}$, soluble fibre intake was $11.9 \pm 5.9 \mathrm{~g}$ and total fibre intake was $40.1 \pm 16.3 \mathrm{~g}$. Mean water intake of the group was $1358 \pm 1090 \mathrm{ml}$. A significant association of water intake was found with frequency of defecation $\left(X^{2}=16.68\right)$, type of stool $\left(X^{2}=32.51\right)$, blood in stools $\left(X^{2}=11.78\right)$ and blockage $\left(X^{2}=9.69\right)(p=<0.05)$. No significant association was seen with stressing $\left(X^{2}=1.50\right)$, satisfactory evacuation $\left(X^{2}=5.16\right)$, urge to defecate $\left(X^{2}=0.25\right)$ and control defecation $\left(X^{2}=4.61\right)$ with water intake $(p>0.05)$. No significant association was found of any defecatory habit and insoluble, soluble or total fibre intake $(p>0.05)$. Water intake is associated with various factors of functional constipation. Awareness to increase water intake to relieve functional constipation needs to be generated.
\end{abstract}

Keywords: Functional Constipation, Water, Dietary Fibre.

\section{INTRODUCTION}

Functional gastrointestinal diseases including chronic constipation are most common illness seen by gastroenterologists. Chronic constipation is symptom based disorder and physicians have been defining constipation objectively using defecation frequency ranging from 3 to 21 bowel movements per week. The most recent definition of functional or chronic constipation is by Rome III criteria which defines constipation as fewer than three bowel movements per week'.
World over using the Rome Criteria, $2-31 \%$ population is affected by chronic functional constipation ${ }^{1,3}$. Similarly prevalence of functional constipation is high in India. In a study from Chandigarh, North India $16.8 \%$ adults with mean age of $38.64 \pm 15.57$ years were reported to be suffering from functional constipation ${ }^{4}$. In rural Bangalore, $8.69 \%$ elderly were reported to be suffering from functional constipation ${ }^{5}$. Prevalence of constipation was as high as $36 \%$ in elderly from Pune city, Western India ${ }^{6}$. 
Thus owing to the large prevalence of functional constipation in India, it is essential to analyse the root cause of functional constipation. Apart from endocrine, metabolic, and neurological disorders, the most common cause of functional constipation is reported to be low dietary fiber intake, inadequate hydration and reduced mobility ${ }^{7}$. To the best of our knowledge, very few studies in India have studied the causes of functional constipation. Mostly low dietary fibre and water intake has been reported to be associated with functional constipation ${ }^{6}$.

Hence, the current study was undertaken with the objective to study the association of water and fibre intake with defecatory habits of patients suffering from chronic functional constipation.

\section{METHODS}

A cross sectional study was conducted in 100 (51 females) adults aged 18-65 years to study the association of water and fibre intake with defecatory habits of patients suffering from chronic functional constipation between September 2013 to November 2013. Patients visiting the gastroenterology outpatient department of King Edward Memorial Hospital, Mumbai with a diagnosed case of chronic functional constipation were recruited. Ethical approval was obtained from institutional ethics committee.

Patients suffering from chronic functional constipation for more than 6 months as diagnosed by gastroenterologist (Dr. A. Shukla) were included in the study. Chronic functional constipation was defined as history of complaints of i) passing fewer than 3 stools a week ii) lumpy or hard stool iii) straining to pass bowel movement iv) suffering from blockage during defecation v) unsatisfactory defecation 1 . Patients with other gastroenterology co-morbidities were excluded from the study.

\section{Outcome Measures}

All measures were recorded between 9.00 am to $1.00 \mathrm{pm}$.

\section{Defecatory Habits}

A pre-tested questionnaire designed by the gastroenterologist (Dr. A. Shukla) was used to collect the information regarding defecatory habits of the patients. Using the questionnaire, information regarding the type of toilet, average defecation time, frequency of defecation, stressing while defecation, presence of blood in stools, blockage during defecation, satisfactory evacuation, urge to defecate, controlling the urge to defecate was collected.

\section{Type of stool}

The Bristol stool scale which classifies the stools in to 7 categories was used to identify the type of stools the patient was passing. The seven categories of stools according to Bristol stool scale were classified as: Type 1: Separate hard lumps, like nuts (hard to pass); Type 2: Sausage-shaped, but lumpy; Type 3: Like a sausage but with cracks

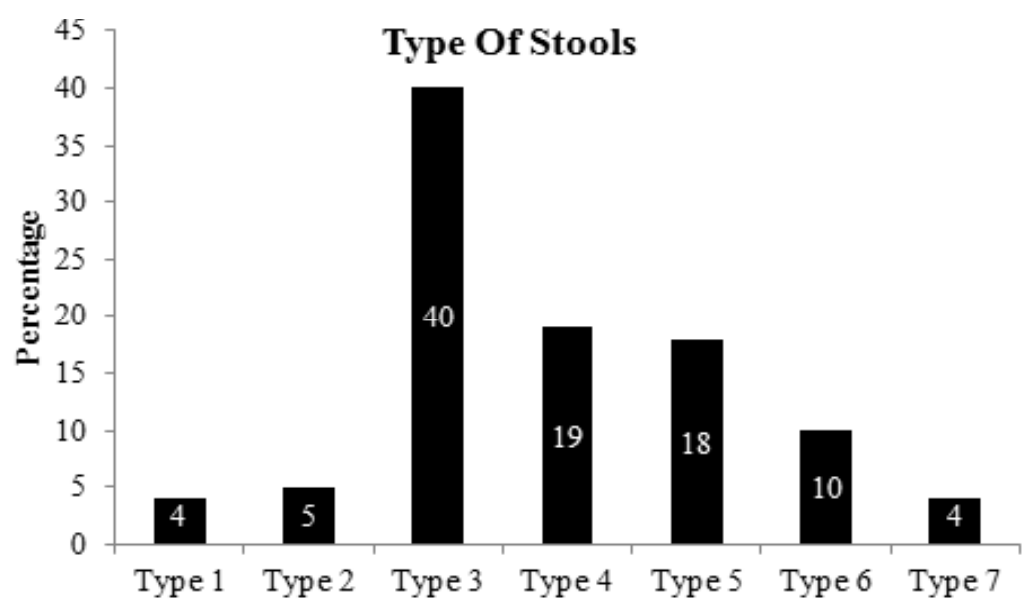

Fig. 1: Type of stool passed according to Bristol Stool Scale Data presented as percentage 
on its surface; Type 4: Like a sausage or snake, smooth and soft; Type 5: Soft blobs with clear cut edges (passed easily); Type 6: Fluffy pieces with ragged edges, a mushy stool; Type 7: Watery, no solid pieces. Entirely liquid ${ }^{8}$

\section{Dietary Fibre intake}

Dietary fibre intake was assessed by $24-\mathrm{h}$ recall on three random days (non-consecutive) of a week, including holiday. Each person was asked about the intake of food items during the day at breakfast, lunch, dinner and snacks, using standard cups and spoons by trained investigators through a face-to-face interview. Dietary fibre intake (insoluble, soluble and total) was calculated by applying the nutritive value tables of the National Institute of Nutrition (NIN), India ${ }^{9}$. Total fluid intake throughout the day was also assessed by demonstrating standard $200 \mathrm{ml}$ glass and patients were asked to report how many glasses they consumed per day. For analysis, fibre intake was classified in to 4 group: insoluble fibre as $<20 \mathrm{~g} /$ day, 20-30 g/day, 30-40g/day and >40 g/day; soluble fibre as $<6 \mathrm{~g} /$ day, 6-10 g/day, $10-15 \mathrm{~g} /$ day and $>15 \mathrm{~g} /$ day and total fibre as <25g/day, 25-40g/day, 40-50g/ day and $>50 \mathrm{~g} /$ day. Fluid intake was classified also classified into 4 groups: $<1000 \mathrm{ml} /$ day, $1000-1500 \mathrm{ml} /$ day, $1500-2000 \mathrm{ml} /$ day and $>2000 \mathrm{ml} /$ day.

\section{Statistical analysis}

Analyses were performed using SPSS software for Windows (version 16.0, 2007, SPSS Inc, Chicago, IL). Data are presented as frequency (percentage). The frequency distributions were tabulated for defecatory habits according to water and fibre intake (insoluble, soluble and total) and

Table 1: History of defecation

\begin{tabular}{lll}
\hline & Yes & No \\
\hline Blood in stools & 25 & 75 \\
Stressing & 90 & 10 \\
Blockage & 80 & 20 \\
Satisfactory evacuation & 30 & 70 \\
Urge to defecate & 73 & 27 \\
Control defecation & 44 & 66 \\
\hline
\end{tabular}

Data presented as percentage were compared using cross tabulations and chisquare test. P-value $<0.05$ was considered to be statistically significant.

\section{RESULTS}

The mean age of the 100 (51 females) patients suffering from chronic constipation 100 adults was $43.9 \pm 14.1$ years.

\section{Defecation History}

Of the 100 patients, $74 \%$ used common toilets and $26 \%$ used personal toilets. $28 \%$ patients required $10-15$ minutes for defecation, $27 \%$ required 15-20 minutes, $20 \%$ patients required $20-25$ minutes and $25 \%$ patients required $25-30$ minutes. When frequency of defecation was assessed, $17 \%$ passed stools everyday, $50 \%$ passed stools atleast 3 times a week, $26 \%$ passed stool 1-3 times a week and $7 \%$ passed stools $<3$ times a week. Figure 1 shows the type of stool passed. As seen in the figure, maximum i.e. $40 \%$ patients passed type 3 stools followed by $19 \%$ passing Type 4 stools and $18 \%$ passing type 5 stools.

Table 1 gives history of other defecatory patterns. As seen in Table 1, $80 \%$ of the patients suffered blockage while passing stools and $90 \%$ stressed to pass stools.

Table 2: Chi-square values for association of insoluble, soluble and total fibre intake with defecatory pattern

\begin{tabular}{lccc}
\hline & $\begin{array}{c}\text { Insoluble } \\
\text { Fibre }\end{array}$ & $\begin{array}{c}\text { Soluble } \\
\text { Fibre }\end{array}$ & $\begin{array}{c}\text { Total } \\
\text { Fibre }\end{array}$ \\
\hline $\begin{array}{lccc}\text { Average Defecation } \\
\text { Time }\end{array}$ & 10.88 & 7.84 & 10.88 \\
$\begin{array}{l}\text { Frequency of } \\
\text { Defecation }\end{array}$ & 6.18 & 13.13 & 9.66 \\
$\begin{array}{l}\text { Type of Stool } \\
\text { Blood in stools }\end{array}$ & 11.18 & 11.18 & 18.15 \\
$\begin{array}{l}\text { Stressing } \\
\text { Blockage }\end{array}$ & 1.40 & 1.40 & 0.381 \\
$\begin{array}{l}\text { Satisfactory } \\
\text { evacuation }\end{array}$ & 2.05 & 3.05 & 3.24 \\
$\begin{array}{l}\text { Urge to defecate } \\
\text { Control defecation }\end{array}$ & 2.05 & 0.38 & 4.51 \\
\hline
\end{tabular}

Data presented as chi-square values 


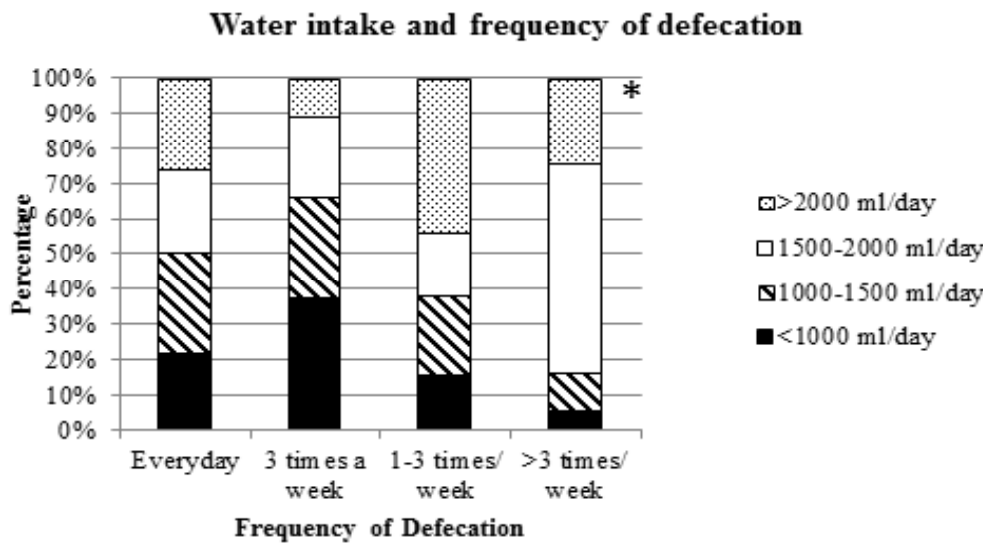

Fig. 2a: Water intake and frequency of defecation Data presented as percentage. * indicates $\mathrm{p}<0.05$

Water intake and type of stools

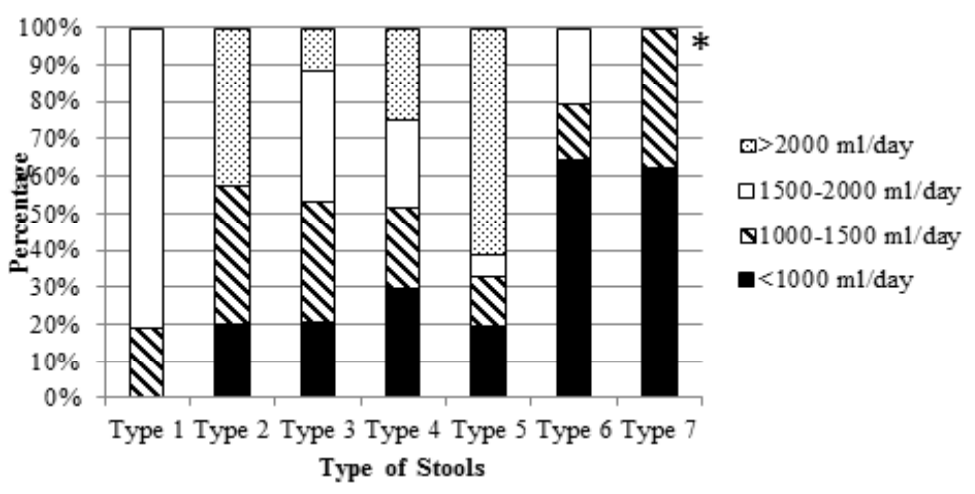

Fig. 2b: Water intake and type of stool Data presented as percentage * indicates $p<0.05$

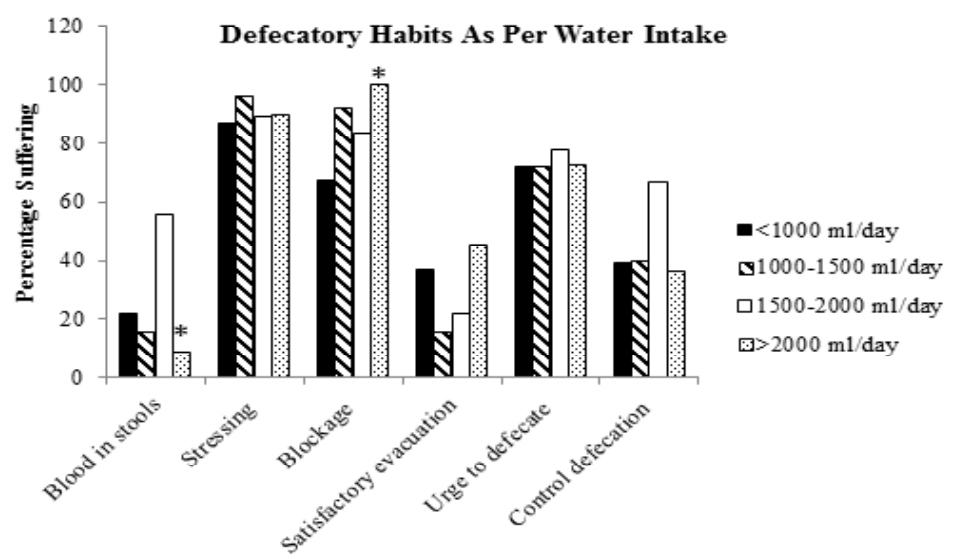

Fig. 2c: Water intake and Other defecatory habits Data presented as percentage * indicates $p<0.05$ 


\section{Dietary Fibre \& Water Intake}

Dietary fibre intake was calculated. Insoluble fibre intake was $28.2 \pm 11.7 \mathrm{~g}$, soluble fibre intake was $11.9 \pm 5.9 \mathrm{~g}$ and total fibre intake was $40.1 \pm 16.3 \mathrm{~g}$. Mean water intake of the group was $1358 \pm 1090 \mathrm{ml}$.

\section{Association of defecatory pattern and water intake:}

An association of defecatory habits with water intake was assessed (Figure 2a-2c). A significant association of water intake was found with frequency of defecation $\left(X^{2}=16.68\right)$ (Figure 2a) , type of stool $\left(X^{2}=32.51\right)$ (Figure $\left.2 b\right)$, blood in stools $\left(X^{2}=11.78\right)$ (Figure 2c) and blockage $\left(X^{2}=9.69\right)$ (Figure $2 c)(p=<0.05)$. No significant association was seen with stressing $\left(X^{2}=1.50\right)$, satisfactory evacuation $\left(X^{2}=5.16\right)$, urge to defecate $\left(X^{2}=0.25\right)$ and control defecation $\left(X^{2}=4.61\right)$ with water intake ( $p>0.05$ ) (Figure 2c). No significant association was seen of average defecation time and water intake $\left(X^{2}=12.26, p>0.05\right)$ (Data not shown).

As association of defecatory habits with insoluble, soluble and total fibre intake was also assessed. No significant association was found of any defecatory habit and insoluble, soluble or total fibre intake ( $p>0.05)$ (Table 2) (Data not shown).

\section{DISCUSSION}

In the current study with the objective to study the association of water and fibre intake with defecatory habits of patients suffering from chronic functional constipation it was found that water intake was significantly associated with frequency of defecation, type of stool, blood in stools and blockage $(p=<0.05)$. No significant association was seen with stressing, satisfactory evacuation, urge to defecate and control defecation with water intake $(p>0.05)$. No significant association was found of any defecatory habit and insoluble, soluble or total fibre intake $(p>0.05)$.

Dietary fibre increases faecal weight by different mechanism based on its physic-chemical properties (water-holding capacity, solubility, particle size, degree of lignification, pentose concentrations, etc.). Insoluble fibre that are not digested, retain water generating high faecal weight, and wetter stools. On the other hand, soluble fibre are fermented by intestinal flora producing which acts as a great stimulus for bacterial growth that make $50 \%$ of faecal weight ${ }^{10}$. Studies have thus associated consumption of dietary fibre to functional constipation ${ }^{7}$. Intake of low dietary fibre than the recommendation is associated with functional constipation. This may be the reason why no such association of dietary fibre with functional constipation was found in the current study as most participants had dietary fibre intake as per the daily recommendations ${ }^{11}$.

Low water intake makes the stools hard and reduces the weight of faeces thereby leading to constipation and aggravating the complications of functional constipation. Low intake of water has been shown to be associated with prevalence of functional constipation ${ }^{12}$. In the current study the water intake was very low and was found to be associated with functional constipation.

One of the short comings of our study is that it's a cross-sectional study and establishes only association of water or dietary fibre intake with functional constipation. Thus, to further evaluate the results of this study, a randomised control trial could be planned to study the effect of extra water or fluid consumption on functional constipation To conclude, water intake is associated with various factors of functional constipation. Awareness to increase water intake to relieve functional constipation needs to be generated.

\section{REFERENCES}

1. Sanchez MI, Bercik P. Epidemiology and burden of chronic constipation. Can J Gastroenterol; 25 Suppl B:11B-15B: (2011)

2. Chang JY, Locke GR 3rd, McNally MA, Halder SL, Schleck CD, Zinsmeister AR,
Talley NJ. Impact of functional gastrointestinal disorders on survival in the community. $A m \mathrm{~J}$ Gastroenterol;105(4):822-32: (2010)

3. Chaud D, Olivon E, Machado A, Abreu E. Prevalence of functional constipation and its 
risk factors among university students (LB328). The FASEB Journal; 28 (1 Supplement LB328)

4. Rajput M1, Saini SK. Prevalence of constipation among the general population: a community-based survey from India. Gastroenterol Nurs.; 37(6):425-9: (2014)

5. Kasthuri A, Hegde SKB, Joseph MA, Rao DP, Gomez G, Sahu A. Prevalence of constipation among elderly in a rural area of Bangalore. IJRRMS; 3(1): (2013)

6. Kaulagekar A, Sathe G. Prevalence of Gastrointestinal diseases among Elderly adn their Dietary Habits with Specific Reference to Constipation. Indian Journal of Gerontology: 19(1): 17-22 (2005)

7. Leung L, Riutta T, Kotecha J, Rosser W. Chronic constipation: an evidence-based review. J Am Board Fam Med; 24(4):436-51: (2011)

8. Longstreth GF, Thompson WG, Chey
WD, Houghton LA, Mearin F, Spiller RC.. Functional bowel disorders. Gastroenterology;130(5):1480-91:(2006)

9. Gopalan C, RamasastriBB, Balasubramanyam SC. Nutritive value of Indian Food. Hyderabad. National Institute of Nutrition, Indian Council of Medical research: (1998)

10. Maffei HV. Chronic functional constipation. Which supplementary fiber to choose? J Pediatr (Rio J); 80(3):167-8: (2004)

11. Morais MB, Vítolo MR, Aguirre AN, FagundesNeto U. Measurement of low dietary fiber intake as a risk factor for chronic constipation in children. J Pediatr Gastroenterol Nutr,29(2):132-5: (1999)

12. Murakami K, Sasaki S, Okubo H, Takahashi Y, Hosoi Y, Itabashi M; Freshmen in Dietetic Courses Study II Group. Association between dietary fiber, water and magnesium intake and functional constipation among young Japanese women. Eur J Clin Nutr, 61(5):61622: (2007) 